\title{
EFFECTS OF INTERFERENCE ON LOCAL PEAK PRESSURES BETWEEN TWO BUILDINGS WITH AN ELLIPTICAL CROSS-SECTION
}

\author{
Michal, FRANEK ${ }^{*}$, Marek, MACÁK²
}

\begin{abstract}
The interference effects on the distribution of external wind pressure coefficient between two high-rise buildings with an elliptical cross section were studied experimentally at the Boundary Layer Wind Tunnel (BLWT) at the Faculty of Civil Engineering STU in Bratislava, Slovakia. Various arrangements of models, which were derived from the breadth ratio, were investigated. The peak value of the external wind pressure coefficient for a stand-alone model was measured and compared with the peak value in the case of interference. The measurements showed that the wind loads on buildings in a close vicinity are considerably different from those on a stand-alone building. The interference effects significantly affect negative pressure zones. The optimal and critical arrangements of buildings were evaluated. The elimination of peak negative external wind pressure coefficients can be reduced by half. On the other hand, the interference effects had a strong impact on increasing the peak value of the negative external wind pressure coefficient, which can be more than roughly double compared to an isolated building.
\end{abstract}

Address

1 Dept. of Building Construction, Faculty of Civil Engineering STU, Bratislava, Slovak Republic

2 Dept. of Mathematics and Descriptive Geometry, Faculty of Civil Engineering STU, Bratislava, Slovak Republic

* Corresponding author: michal.franek@stuba.sk

Key words

- Effects of interference,

- Wind tunnel,

- External wind pressure coefficient,

- Elliptical high-rise building.

\section{INTRODUCTION}

Interference effects can disturb the air flow in front of a structure. This phenomenon is generated by the geometry, layout and orientation of the surrounding structures and objects. Measurements by various researchers have shown that the wind loads on buildings close to each other are considerably different from those on an isolated building. The earliest work on this issue dates back to the 1930s (Harris, 1934). Measurements were made of the wind pressure over a model of the Empire State Building in New York City. It was concluded that the torque moment was two times higher when it was placed two blocks in front of the building. Bailey and Vincent (1943) found a relationship between the wind speed and pressure distribution on the surface of pitched and flat roofs when they were fully exposed to approaching wind and when there was an obstacle close to the building. Studies of interference effects resumed in the 1960s. In 1965, three out of eight cooling towers at Ferrybridge in England collapsed due to the effects of interference. During the 1980s, research activities were focused on the implementation of interference effects by the existing codes and standards (Holmes and Best, 1979; Stathopoulos, 1984; Bailey and Kwok, 1985; Kwok, 1989). Wind tunnel measurements by Gowda and Sitheeq (1993) indicated that a downstream building is fully submerged in the shear boundary layer of an upwind building when the spacing between buildings is less. Thus, the whole surface of the downstream building suffered from higher negative pressures. Recent experimental research on the effects of interference (Kim et al., 2011, 2013, 2015; Mara et al., 2014; Yu et al., 2015; Yan and $\mathrm{Li}, 2016$ ) has studied the distribution of pressure using the mean and peak values of the external wind pressure coefficient. Various shapes of high-rise buildings and the spacing between them were investigated. The results proved that interference effects had a strong impact on a negative pressure zone. This value has a crucial impact on the design of a façade. Current work includes studying the interference, topology, and pedestrian comfort along with the issue of modelling the atmospheric boundary layer from a statistical point of view and computational fluid dynamics (CFD) (Blocken, 2015; Blocken et al., 
2016). To fully understand interference effects, wind tunnel tests are required. These tests are limited and only cover partial scenarios. An advanced state-of-the-art method uses machine learning methods ( $\mathrm{Hu}$ et al., 2020). This article discusses the machine learning techniques that can resolve conflicts between wind tunnel tests and save testing time and costs. In this respect, it should first be noted that the development of these techniques is in its initial phase.

The first pressure measurement techniques of 2D bluff bodies with an elliptical cross-section were developed by Wiland (1968) and Dikshit (1970). Force balance measurements and characteristics of aerodynamic forces were carried out by Takeuchi et al. (2009); Alonso et al. (2010); and Foncesa et al. (2013). Afreem et al. (2015) studied the pressure distribution on an elliptical cross-section of a high-rise building subjected to direction from various winds.

After studying the available literature and existing standards, we determined that there was not sufficient research on high-rise buildings with elliptical cross sections in cases of interference. It should be added that current trends in the building industry feature an increasing number of buildings with circular or elliptical shapes, including in Slovakia. The Eurocode building code (STN EN 1991-1-4, 2007) does not have a procedure for handling buildings with elliptical cross-sections. It is necessary to undertake a specific wind study because the results from the Eurocode approach can be inadequate. However, there are some applications in the New Zealand code (ASNZS1170.2, 2011). The India code of practice (IS:875, 1987) only specifies the force coefficients for two wind directions.

\section{EXPERIMENTAL SETUP}

The pressure measurements were conducted in a low-speed Boundary Layer Wind Tunnel (BLWT) at the Faculty of Civil Engineering STU in Bratislava. This type of wind tunnel simulates the actual characteristics of the Atmospheric Boundary Layer (ABL). The cross dimensions of the test section is $2.6 \times 1.6 \mathrm{~m}$. The length of the wind tunnel is $26.3 \mathrm{~m}$.

\subsection{Characterization of an $\mathrm{ABL}$ and instrumentation}

The following characterizations are used for pressure measurements. The ABL was generated by Counihan generators, a barrier, and a uniformly rough field with a dimpled membrane. According to the Eurocode (STN EN 1991-1-4, 2007), the characterization of an ABL with an aerodynamic roughness length of $z_{0}=0.7 \mathrm{~m}$ belongs between category III and IV. After comparing the profile of the mean wind velocity and turbulence intensity, a better match was determined to be terrain Categories III. The characteristics of the mean wind velocity and turbulence intensity is in Fig. 1. The scaling of the ABL was derived from a long-term series measurement of the velocity and then converted to the integral length scale $L_{u x}$. According to the measurements, the length of the scale was 1:390. The dynamic similarity, which is described by the non-dimensional power spectral density, can be seen in Fig. 2. The velocity scale was 1:2.6. Based on Eq. (1):

$$
\lambda_{f}=\lambda_{L} \lambda_{u}
$$

where $\lambda_{f}$ is the frequency scale in [-]; $\lambda_{L}$ is the length scale in [-]; and $\lambda_{u}$ is the velocity scale in [-], it follows that the frequency scale corresponded to a value of $1: 150$. This means that a $20 \mathrm{~s}$ measurement in the wind tunnel was equal to $3000 \mathrm{~s}$ in a full scale. The mean wind velocity was measured at two thirds of the height of the model, and was equal to $12.07 \mathrm{~m} / \mathrm{s}$. This height was chosen on the basis of the maximum value of the wind loads (Franek and Žilinský, 2017), which

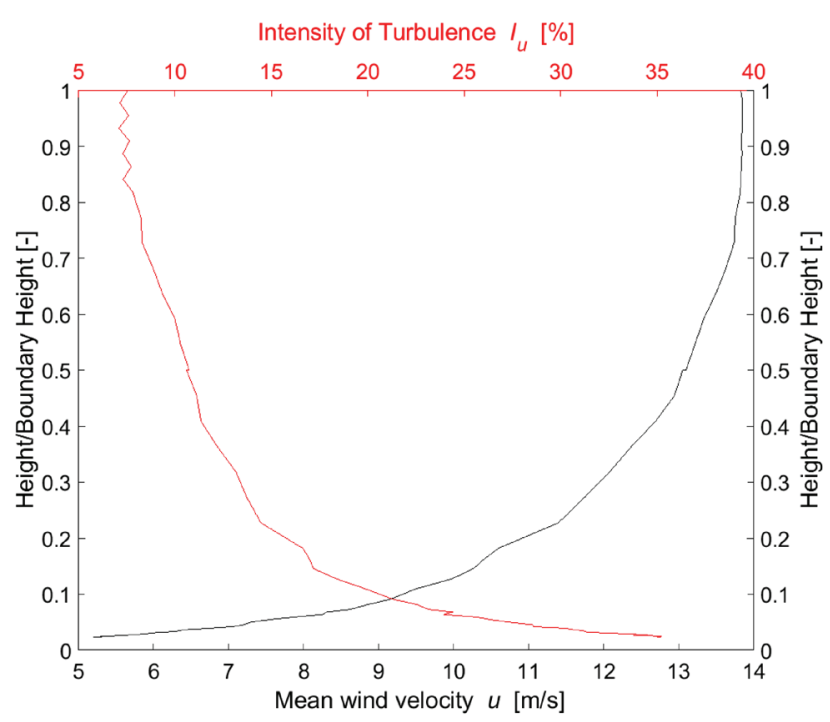

Fig. 1 Characterization of ABL, black curve - mean wind velocity, red curve - intensity of turbulence

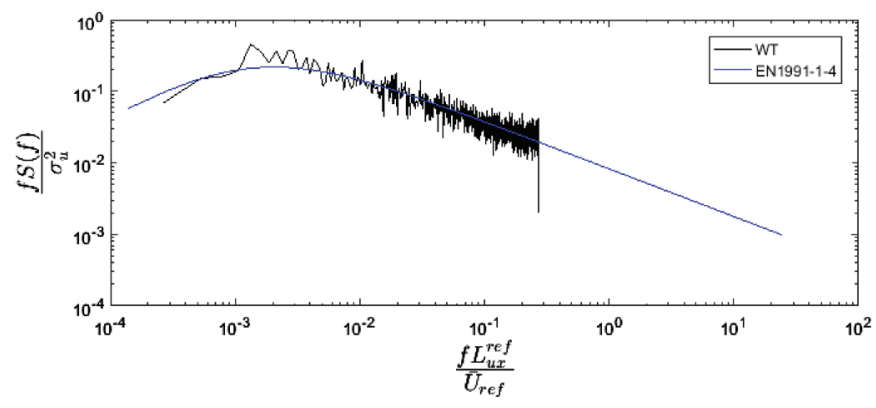

Fig. 2 Non-dimensional power spectral density at two thirds of the height of the model

is the position of the center of gravity of the wind pressure. It was observed that for a isolated model with an elliptical cross section, the maximum value of the pressure and suction occurred in this area. The Reynolds number $(R e)$ depends on the characteristic dimensions of the model and was in a range of $5.1 \times 10^{4}-1.3 \times 10^{5}$ for this experiment. The application of the roughness on the model was used to eliminate the undesirable effect of the low Re number, according to Achenbach and Heinecke (1981).

\subsection{Definition of the models}

Two types of experimental models were used for the pressure measurements, i.e., one with pressure taps, referred to as the principal building, and the second without any pressure taps, and referred to as the interfering building. The models had the same geometry. The dimensions were $64 \times 162 \times 175 \mathrm{~mm}$ (width $\times$ length $\times$ height $)$, which corresponded to a ratio of $1: 2.5: 2.7$. The geometry of the model was inspired by an existing complex of high-rise buildings in the Bratislava region. This ratio was chosen after the geometry analysis (Franek, 2017). The geometric scale was equal to the ABL scaling, which is 1:390. The arrangement and position of the pressure taps were at two thirds of the height, see Fig. 3. The models used in this experiment were all rigid models.

A mesh was created with the distance and position of the interference building as half of the width of the model. It represented a total of 42 positions of the interference building. The wind direction for each measurement was from $0^{\circ}$ to $180^{\circ}$ with increments of $10^{\circ}$ 

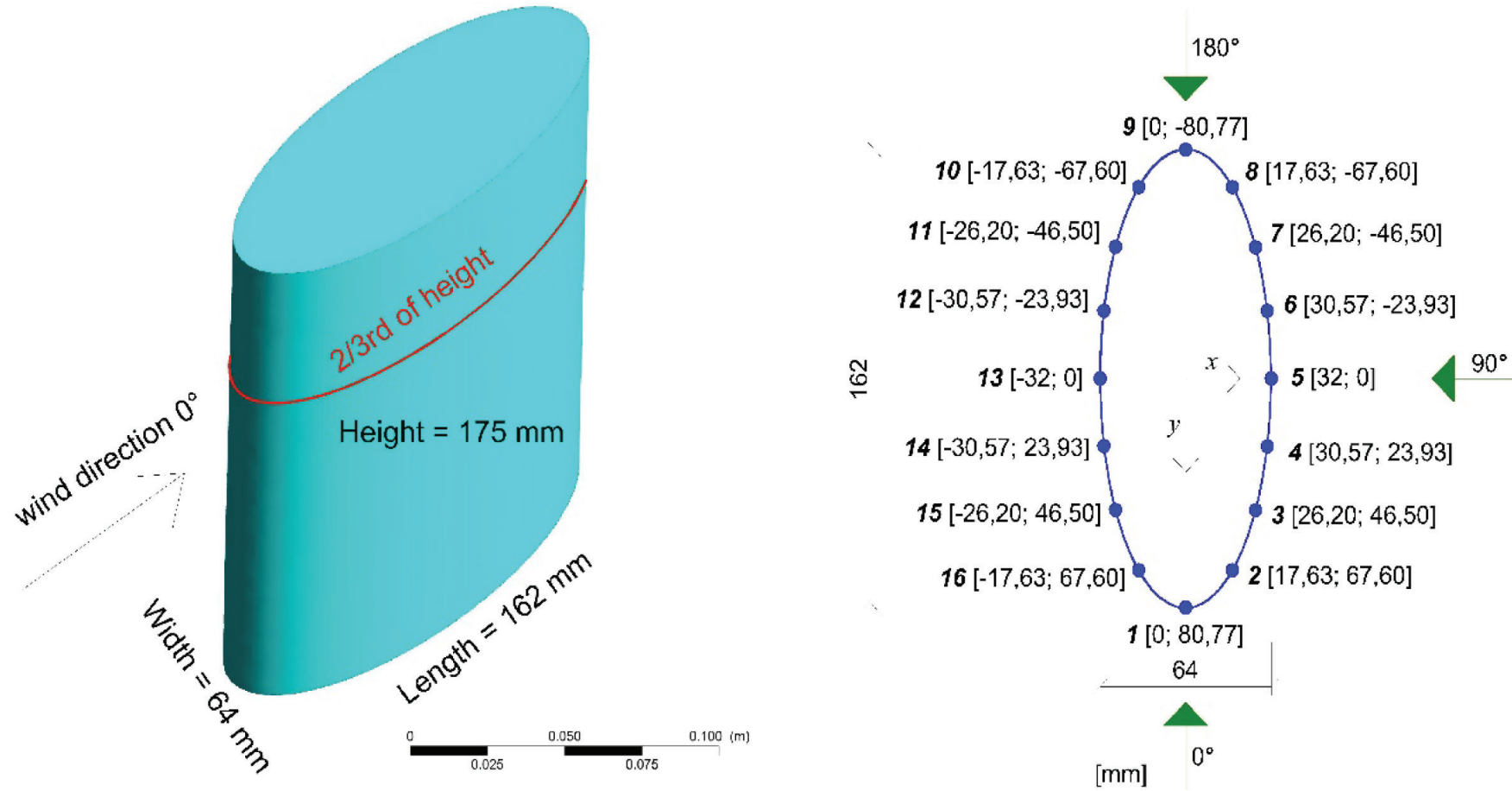

Fig. 3 Position of the pressure taps on the model with an elliptical cross section
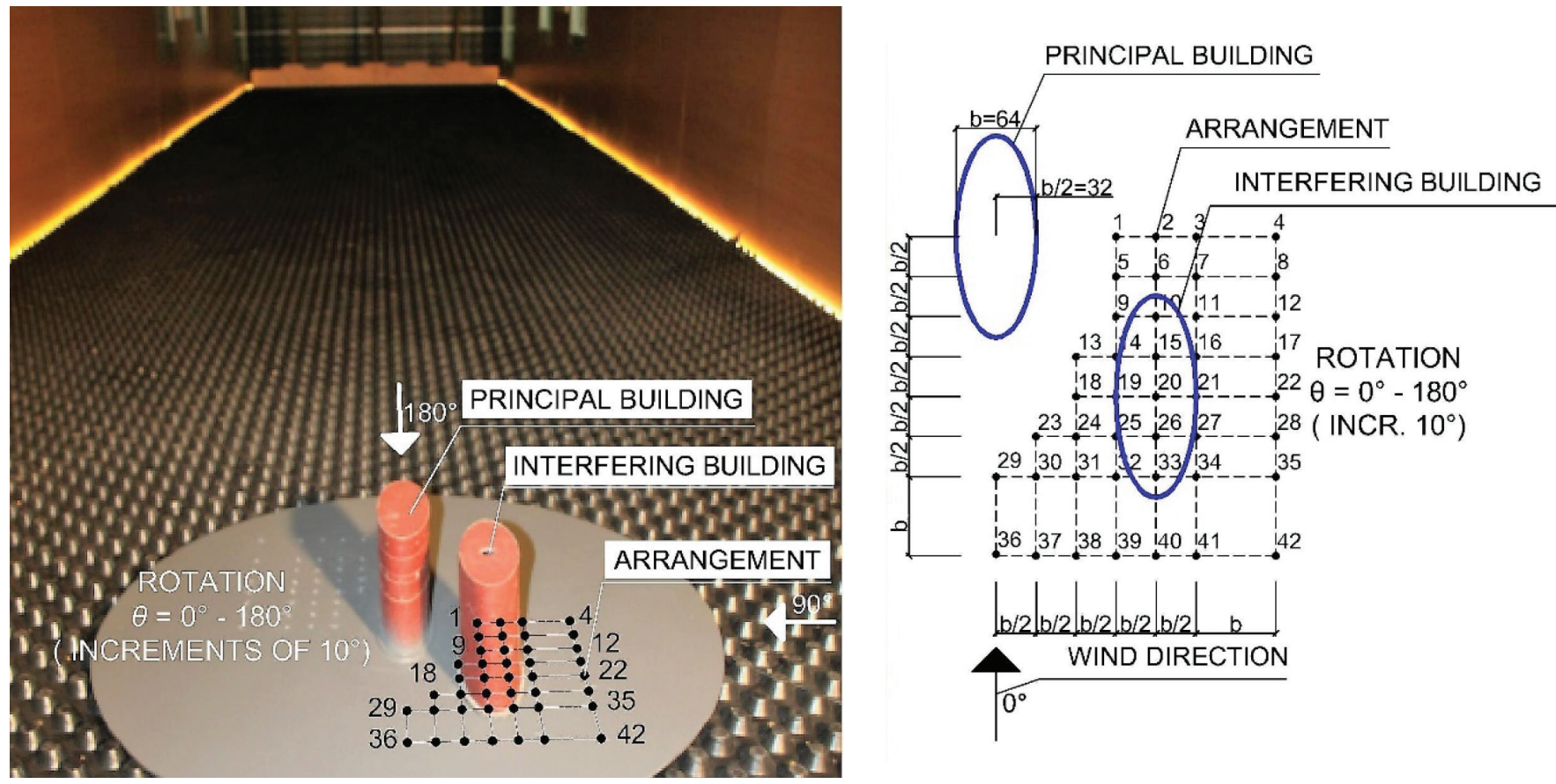

Fig. 4 Arrangement of the experiment in BLWT

(see Fig. 4). The blockage ratio was $1.36 \%$, which was below the $5 \%$ value, so the correction should not be done according to Choi (1998), which is defined as the ratio of a model's projection area to a wind tunnel's cross-section area.

\subsection{Pressure measurement and determination of the peak value of the pressure coefficient}

The pressure measurement tests were carried out on the rigid model with pressure taps. These taps were conducted with vinyl tubes and a circular pneumatic connector to the Scanivalve DSA 3217 pressure scanner. This equipment had 16 temperature-compensated piezoresistive pressure transducers with a pneumatic calibration valve, RAM, 16 bit A/D converter, and a microprocessor in a compact self-contained module. The sampling speed per single measurement was 500 samples. This corresponded to a sampling frequency for each tap equal to $25 \mathrm{~Hz}$. To eliminate the low pass noise, the prescribed lengths of the tubing system and connector were used. The duration of each measurement was $20 \mathrm{~s}$. Each measurement was recorded twice to avoid errors. For each measurement the time series of the differential pressure between the reference tap in the Prandtl tube and the taps on the model 
was recorded. The pressure in the Prandtl tube represented free stream static pressure. The value of the pressure on the model was the local surface pressure. According to Eq (2), the value of the external wind pressure coefficient (Cermak, 1999) was defined as:

$$
c_{\mathrm{pe}}=\frac{p-p_{\mathrm{s}}}{\frac{1}{2} \rho u_{\mathrm{ref}}^{2}}
$$

where $c_{\mathrm{pe}}$ is the external wind pressure coefficient in [-]; $p$ is the local surface pressure in the tap in $\mathrm{Pa} ; p_{\mathrm{s}}$ is the free stream static pressure in $\mathrm{Pa} ; \rho$ is the physical density of the air in $\mathrm{kg} / \mathrm{m}^{3}$; and $u_{\text {ref }}$ is the free stream reference velocity; in our case that was at two thirds of the height of the model in $\mathrm{m} / \mathrm{s}$.

The mean, minimum, maximum and RMS value of the $c_{\mathrm{pe}}$ was calculated from Eq (2). An illustration of the time history measurements for one tap can be seen in Fig. 5. There are various methods for observing the peak value, and they depend on wheter the pressure distribution reproduces a generalized non-Gaussian or Gaussian distribution. Nowadays, many studies still accept distribution of the wind pressure as a Gaussian process. This approach is effective when the overall effect of the random wind pressure field on an area is considered (Quan et al., 2014). Peterka, Cermak (1975) and Kareem (1978) showed that, in an area where the mean pressure coefficients are lower than -0.25 , the wind pressure is in general skewed. Many applications in wind engineering use the estimation of the extreme value by Davenport (1964). This research observed the peak values of the wind obtained with the cross-leveling method in which the fluctuating wind pressures are assumed to be Gaussian. This is known as the peak factor or the Davenport method. This method was used for the evaluation of the peak external wind pressure coefficients. It was observed that the peak response of most structures to gusts may be expected to range from a 3.5 to 4.5 standard deviation of the response in excess of the mean response. It depends on the duration of the wind storm. Our analysis used the formula for the duration of a 10 min storm where the peak value in Eq. (3) (Davenport, 1964) is described as:

$$
\text { peak } c_{p e}=\text { mean } c_{p e}+3.5 \mathrm{STD}
$$

where $c_{\mathrm{pe}}$ is the external wind pressure coefficient in [-]; the peak is the peak value; the mean is the mean value; and STD is the standard deviation.

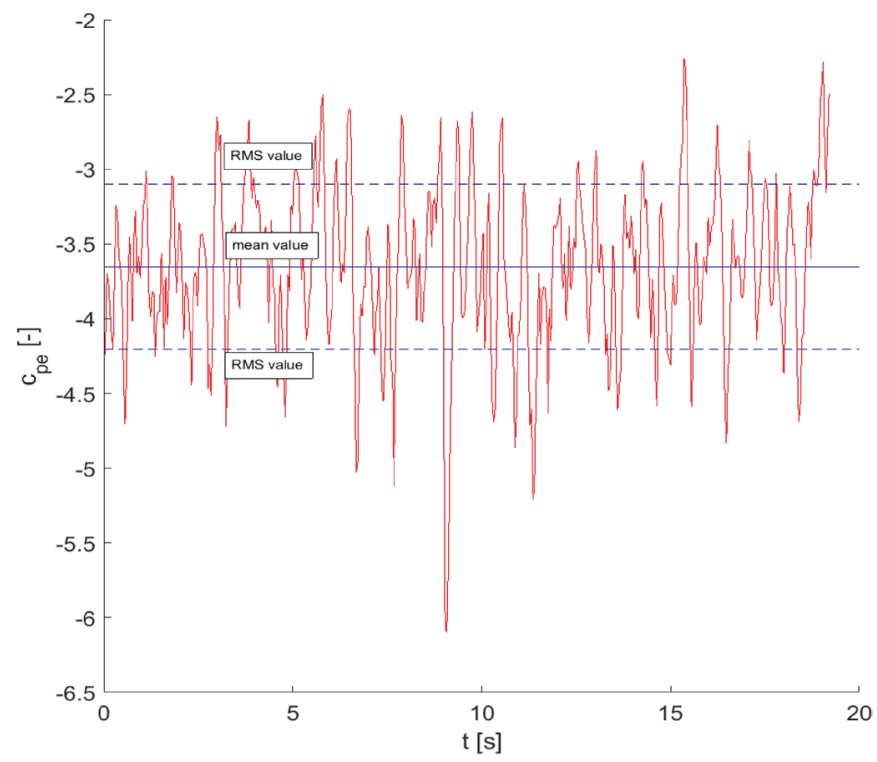

Fig. 5 Time history of the external wind pressure coefficients from the pressure tap

\section{RESULTS AND DISCUSSION}

\subsection{Interference factor based on the largest external peak wind pressure coefficient across the entire level}

The measurements indicated that the elliptical interference building had a stronger effect on the negative peak pressure. Thus for the next study of the interference, only the minimum value of peak $c_{\mathrm{pe}}$ was used. To compare the minimum value for the isolated building and in the case of interference, the interference factor (IF) (Yu et al.) was used. It is described as follows:

$\mathrm{IF}=\frac{\text { min value of peak } c_{p e} \text { with interfering building }}{\text { min value of peak } c_{p e} \text { without interfering building }}$

\subsection{Methodology for an evaluation of the interference effect}

The methodology used in this study was as follows: From each measurement of the 42 positions of the interference building (see Fig. 4), we found the minimum value of the peak $c_{\text {pe }}$ from 16 pressure taps at two thirds of the height of the principal building with the interfering building. This value was compared with the minimum value of peak $c_{\mathrm{pe}}$ for the isolated building with the same incident flow and calculated IF. The measurements were analyzed for 19 wind directions. The IF was used as a parameter for our assessments. A mesh with a value of IF for each wind direction and the values of peak $c_{\text {pe }}$ with the wind direction was created for a better understanding and processing of the high amount of data (see Figs. 6 and 7).

\subsection{Focusing on the value of IF}

A mesh with the values of IF was created for each measurement. For the high amount of data, IF was assessed in this section from the point of view of the wind direction. Nineteen wind directions, each with 42 positions of the interfering building were analyzed. The optimal wind direction contains the minimum values of IF close to zero. The critical wind directions contain the maximal local values of IF. At first we started with the optimal wind direction (see Fig. 6). When the wind direction of $20^{\circ}$ was assessed, it could be seen that the interference building in certain positions, particularly in front of the principal building, could rapidly reduce the peak value of $c_{\mathrm{pe}}$. The measurements showed that it could be around $44 \%$, which was significant and that it was worthwhile to investigate this issue. These conditions were apparently caused by the shielding of the interference building and the generation of an unstable vortex area, i.e., a wake. While it was true on one hand that this wake could reduce the peak $c_{\mathrm{pe}}$, on the other hand, it could adversely affect the overall dynamic load on the building. This phenomena occurred only for certain positions of the interference building, mostly in front of or in a close vicinity. The impact of the wake depended on the shape, wind direction, and height of the building.

On the other hand, if the critical wind direction (see Fig 7) was considered in certain positions, the increasing minimum value of peak $c_{\text {pe }}$ up to $180 \%$ could be seen. In this case the combination of various effects could be seen. There was a wake behind the interference object with a combination of the decreasing of the flow near the passages between the swaying building.

\subsection{Focusing on the value of the peak cpe}

The IF could clearly clarify the distinction between the isolated building and in the case of any interference, but it was still a dimen- 


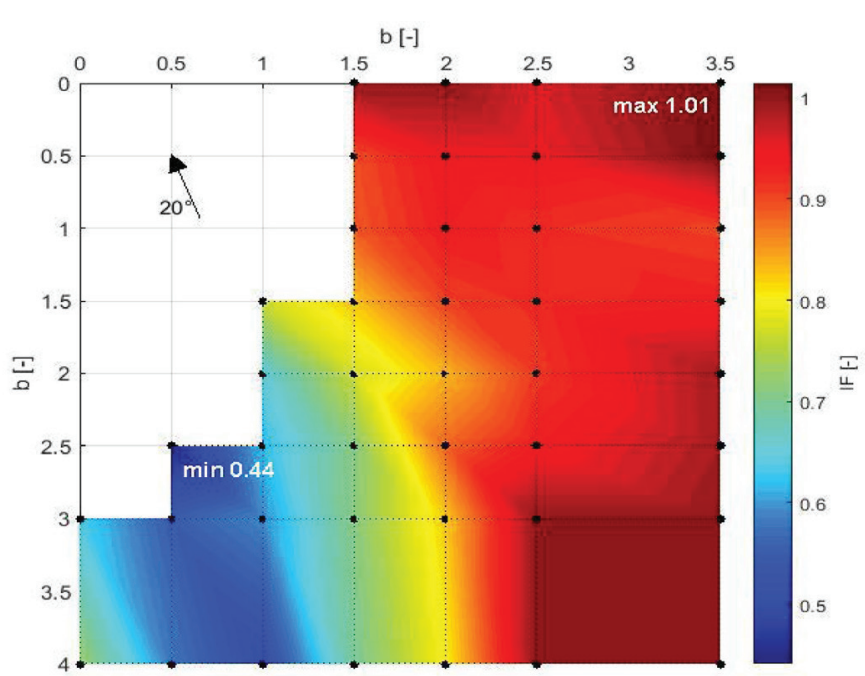

Fig. 6 Mesh with values of IF for a $20^{\circ}$ optimal wind direction

sionless number. The IF did not contain the specific value of the peak $c_{\mathrm{pe}}$ in the results. It is necessary to calculate with the actual value of the $c_{\mathrm{pe}}$ for the design of the cladding system on a high-rise building, because this value has a strong impact on the wind loads. Let us look at a minimum positive value of $c_{\mathrm{pe}}$, which means the opti-

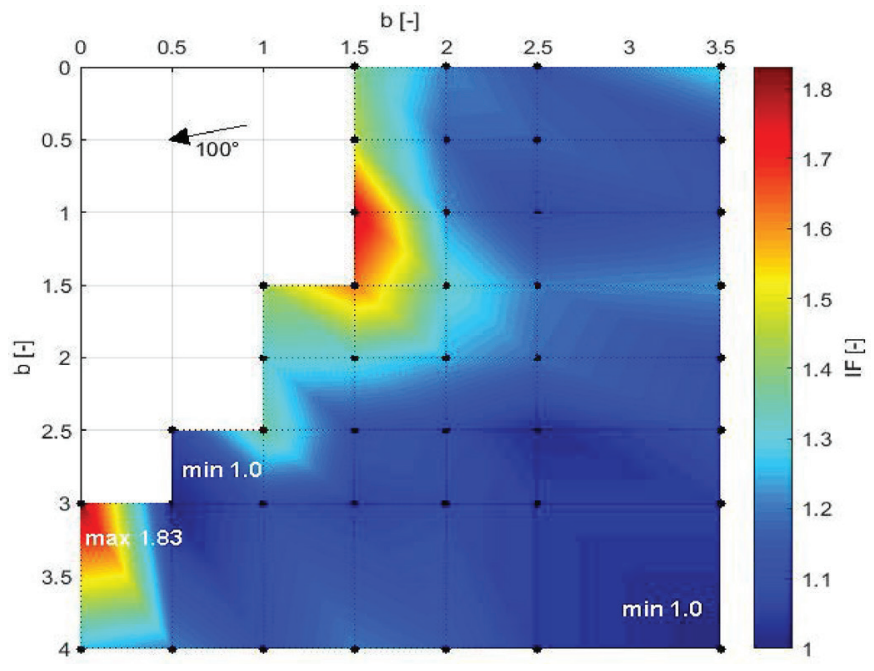

Fig. 7 Mesh with values of IF for a $100^{\circ}$ critical wind direction

mal arrangement, and a minimum negative value of peak $c_{\mathrm{pe}}$, which means a critical arrangement. These results were processed as seen in Tab. 1. The optimal position appeared in cases when the interference building created a shield before the principal building, but only for certain wind directions. A critical arrangement occurred when the

Tab. 1 Summary table with comparisons of $c_{p e}$ for an isolated building, a building in the case of interference, and a normative approach for a cylindrical building

\begin{tabular}{|c|c|c|c|c|c|c|c|c|c|c|}
\hline \multirow{4}{*}{ 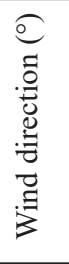 } & \multicolumn{2}{|c|}{ Isolated building } & \multicolumn{4}{|c|}{ Interference effect } & \multicolumn{4}{|c|}{ STN EN 1991-1-4 Cylindrical building } \\
\hline & \multirow{3}{*}{$\begin{array}{c}\text { Max value of } c_{\mathrm{pe}} \\
{[-]}\end{array}$} & \multirow{3}{*}{$\underset{[-]}{\operatorname{Min} \text { value of } c_{\mathrm{pe}}}$} & \multirow{3}{*}{$\underset{[-]}{\text { Max value of } c_{\mathrm{pe}}}$} & \multirow{3}{*}{$\begin{array}{l}\dot{0} \\
0 \\
\stackrel{0}{0} \\
0 \\
\dot{z}\end{array}$} & \multirow{3}{*}{$\begin{array}{c}\text { Min value of } \\
c_{\mathrm{pe}}[-]\end{array}$} & \multirow{3}{*}{$\begin{array}{l}\dot{0} \\
\dot{0} \\
\dot{L} \\
\dot{0} \\
\dot{Z}\end{array}$} & \multirow{3}{*}{ 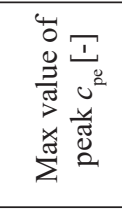 } & \multirow{2}{*}{\multicolumn{3}{|c|}{$\begin{array}{c}\text { Min value of } c_{\mathrm{pe}} \\
\text { Reynolds number }\end{array}$}} \\
\hline & & & & & & & & & & \\
\hline & & & & & & & & $\begin{array}{l}n \\
0 \\
x \\
n \\
n\end{array}$ & $\begin{array}{l}0 \\
\stackrel{0}{x} \\
\stackrel{x}{1} \\
\end{array}$ & $\begin{array}{l}\text { io } \\
\stackrel{0}{x} \\
\text { iv }\end{array}$ \\
\hline 0 & 0.67 & -0.52 & 0.68 & 18 & -1.14 & 1 & \multirow{19}{*}{1.0} & \multirow{19}{*}{-2.2} & \multirow{19}{*}{-1.9} & \multirow{19}{*}{-1.5} \\
\hline 10 & 0.33 & -0.90 & 0.73 & 24 & -1.13 & 1 & & & & \\
\hline 20 & 0.58 & -1.53 & 0.59 & 18 & -1.28 & 22 & & & & \\
\hline 30 & 0.70 & -2.03 & 0.65 & 12 & -1.75 & 12 & & & & \\
\hline 40 & 0.61 & -1.39 & 0.69 & 17 & -1.97 & 36 & & & & \\
\hline 50 & 0.64 & -0.81 & 0.67 & 2 & -2.01 & 3 & & & & \\
\hline 60 & 0.66 & -0.60 & 0.66 & 2 & -1.78 & 2 & & & & \\
\hline 70 & 0.64 & -0.50 & 0.66 & 13 & -2.48 & 24 & & & & \\
\hline 80 & 0.71 & -0.49 & 0.72 & 14 & -2.52 & 24 & & & & \\
\hline 90 & 0.66 & -0.48 & 0.68 & 14 & -2.50 & 13 & & & & \\
\hline 100 & 0.71 & -0.49 & 0.70 & 8 & -2.67 & 19 & & & & \\
\hline 110 & 0.64 & -0.50 & 0.65 & 8 & -2.20 & 19 & & & & \\
\hline 120 & 0.66 & -0.60 & 0.66 & 15 & -2.40 & 13 & & & & \\
\hline 130 & 0.64 & -0.81 & 0.68 & 2 & -3.38 & 26 & & & & \\
\hline 140 & 0.61 & -1.39 & 0.66 & 26 & -3.30 & 13 & & & & \\
\hline 150 & 0.70 & -2.03 & 0.65 & 20 & -2.48 & 13 & & & & \\
\hline 160 & 0.58 & -1.53 & 0.52 & 34 & -2.15 & 13 & & & & \\
\hline 170 & 0.33 & -0.90 & 0.63 & 18 & -1.74 & 13 & & & & \\
\hline 180 & 0.67 & -0.52 & 0.68 & 18 & -1.14 & 1 & & & & \\
\hline
\end{tabular}


interference building slightly swayed and passages between the two buildings was created. Tab. 1 also shows the normative values of $c_{\mathrm{pe}}$. It is clear from the results that the normative approach for an elliptical building in interference is not sufficient for the design of a cladding system because the local value of the $c_{\mathrm{pe}}$ is considerably higher.

\subsection{Optimal and critical distances between the models and their impact on the IF and peak $c_{\text {pe }}$}

The results show that the optimal and critical distances were strongly affected by the wind directions. Another aspect was the height of the building. In general, a building or construction, which is in a close vicinity with another building, can strongly change the flow pattern. It can be recalled that the impact on the IF and peak $c_{\mathrm{pe}}$, and not the impact on the variations of the pressure distribution, was evaluated. Our research found from all the wind directions, that the distance of the interfering building above 4B (in our case, it was the width) had a low impact on the principal building. In particular, some wind directions showed a low or zero impact at a distance at twice the models' width. On the other hand, some results showed a strong impact at a distance three fifths of the width.

\section{CONCLUSIONS}

Based on the experimental measurements of the interference effects for two high-rise buildings with elliptical cross sections and their impact on the peak value of $c_{\mathrm{pe}}$, some conclusions could be obtained as follows:

- In the case of the shielding and elimination of the pressure, the minimum peak value of $c_{\mathrm{pe}}$ can be reduced by up to $40 \%$. This reduction occurred when the interference building created something like a shield and the principal building was in a leeward zone. Behind the interference building a wake originated; it was a fully turbulent flow that could have a positive impact on the pressure distribution of the principal building.

- However, when the interference building slightly swayed and remained at a critical distance, the wake partially affected the principal building. These unstable conditions might result in increasing the minimum value of the peak $c_{\mathrm{pe}}$. The minimum peak $c_{\mathrm{pe}}$ could increase up to $180 \%$ compared to the isolated building.

- In general, the interfering building had a strong impact on the principal building at a distance less than 4 times the width of the elliptical building.

- Our applicable code does not offer a handling procedure for a building with an elliptical cross-section. If the procedure for a cylinder is used, the local mean value of $c_{\mathrm{pe}}$ is underestimated.

- Another topic for future research could be the mutual interaction between the interfering and principal building.

It was difficult to arrive at a general conclusion. This phenomenon had a large amount of variables. We can recommend the optimal arrangement of specific elliptical buildings from our experimental study. The critical zones of existing buildings or recommendations for the future design of a group of high-rise buildings with elliptical cross-sections can be determined from our analysis.

\section{Acknowledgments}

This work was supported by the Slovak Research and Development Agency under Contract No. APVV-16-0126 and by the Scientific Grant Agency of the Ministry of Education, Science, Research and Sport of the Slovak Republic and the Slovak Academy of Sciences in VEGA project 1/0113/19.

\section{REFERENCES}

AS/NZS 1170.2 (2011) Structural Design Actions, Part 2 - Wind actions.

Achenbach, E. - Heinecke, E. (1981) On vortex shedding from smooth and rough cylinders in the range of Reynolds number $6 \times 10^{3}$ to $5 \times 10^{6}$. Journal of Fluid Mechanics. vol. 109, pp. 239251. Available on: https://doi.org/10.1017/S002211208100102X, (accessed at 10/01/2018).

Alonso, G. et al. (2010) On the galloping instability of two-dimensional bodies having elliptical cross-sections. Journal of Wind Engineering and Industrial Aerodynamics. vol. 98, pp. 438-448.

Bailey, A. - Vincent, N. D. G. (1943) Wind-pressure on buildings including effects of adjacent buildings. Journal of the Institution of Engineers. vol. 20, pp. 243-475.

Bailey, P. A. - Kwok, K. C. S. (1985) Interference Excitation of Twin Tall Buildings. Journal of Wind Engineering and Industrial Aerodynamics. vol. 21, pp. 328-338.

Cermak, J. E. et al. (1999) Wind Tunnel Studies of Buildings and Structures: ASCE Manuals and Reports on Engineering Practice. Virginia: American Society of Civil Engineers. ISBN 0-78440319-8.
Choi, C. K. et al. (1998) Comparison between the CFD and wind tunnel experiment for tall building with various corner shapes. Proceedings of the Fifth International Conference on Tall Building, Hong Kong, 632-637.

Blocken, B. (2015) Computational Fluid Dynamics for urban physics: Importance, scales, possibilities, limitations and ten tips and tricks towards accurate and reliable simulations. Journal of Building and Environment, [online]. Vol. 91, pp. 219-245. Available on: https://doi.org/10.1016/j.buildenv.2015.02.015, (accessed at 04/10/2019).

Blocken, B. et al. (2016) Pedestrian-level wind conditions around buildings: Review of wind-tunnel and CFD techniques and their accuracy for wind comfort assessment. Journal of Building and Environment, [online]. Vol. 100, pp. 50-81. Available on: https://doi.org/10.1016/j.buildenv.2016.02.004, (accessed at 04/10/2019).

Davenport, A. G. (1964) Note on the distribution of the largest value of random function with application to gust loading. Institution of Civil Engineers, vol. 28, paper no. 6739, pp. 187-196. 
Dikshit, A. K. (1970) On the Unsteady Aerodynamics of Stationary Elliptic Cylinder during Organized Wake Condition. Dissertation thesis.

Franek, M. (2017) Impact of the interference effects on the distribution of the external pressure coefficient for an elliptical cross-section high-rise buildings, Dissertation thesis, Bratislava, Faculty of Civil Engineering in Bratislava, Slovakia [in Slovak].

Franek, M. - Žilinský, J. (2017) Maximum wind loads on the isolated cylinder. MABD 2017, Brno University of Technology, pp. 96-101.

Fonseca, F. B. et al. (2013) Flow around elliptical cylinders in Moderate Reynolds Numbers. Proc. Of the $22^{\text {nd }}$ International Congress of Mechanical Engineering (COBEM 2013), Nov. 3-7, Ribeirão Preto, SP, Brazil, pp. 4089-4100.

Gowda, B. H. L. - Sitheeq, M. M. (1993) Interference effects on the wind pressure distribution on prismatic bodies in tandem arrangement. Indian J. Technol. 31, pp. 485-495.

Harris, C. L. (1934) Influence of Neighboring Structures on the Wind Pressure on Tall Buildings. Bureau of Standards Journal Res. 12 [online], pp. 103-118.

Holmes, J. D. - Best, R. J. (1979) A Wind Tunnel Study of Wind Pressures on Grouped Tropical Houses. Queensland: Department of Civil and Systems Engineering, James Cook University of North Queensland, N.Z. Report No. BS 29.

Hu, G. et al. (2020) Deep learning-based investigation of wind pressures on tall building under interference effects. Journal of Wind Engineering and Industrial Aerodynamics, [online]. vol. 201, 104138. Available on: https://doi.org/10.1016/j. jweia.2020.104138, (accessed at 11/07/2020).

IS: 875 (1987) Code of practice for design loads (other than Earthquake) for Buildings and structures- Part 3: Wind loads. BIS, New Delhi, India.

Kareem, A. (1978) Wind excited motion of tall buildings [Ph.D. dissertation in partial fulfillment of the degree of doctor of philosophy], Colorado State University, Fort Collins, Col, USA.

Kim, W. S. et al. (2011) Interference effects on local peak pressures between two buildings. Journal of Wind Engineering and Industrial Aerodynamics [online]. vol, 99, pp. 584-600. Available on: http://dx.doi.org/10.1016/j.jweia.2011.02.007, (accessed at 08/06/2018).

Kim, W. S. et al. (2013) Simultaneous measurement of wind pressures and flow patterns for buildings with interference effect. Journal of Advances in Structural Engineering. vol. 16 (2), pp. 287-305.

Kim, W. S. et al. (2015) Interference effects on aerodynamic wind forces between two buildings. Journal of Wind Engineering and Industrial Aerodynamics [online]. vol. 147, pp. 186-201. Available on: https://doi.org/10.1016/J.JWEIA.2015.10.009, (accessed at $08 / 06 / 2018$ )

Kwok, K. C. S. (1989) Interference Effects on Tall Buildings. Proc. 2nd Asia Pacific Symp Wind Engng. Beijing. vol. 1, pp. 446-453.

Mara, T. G. et al. (2014) Aerodynamic and peak response interference factors for an upstream square building of identical height. Journal of Wind Engineering and Industrial Aerodynamics [online]. vol. 133, pp. 200-210. Available on: http://dx.doi. org/10.1016/j.jweia.2014.06.010, (accessed at 08/06/2018).
Peterka, J. A. - Cermak, J. E. (1975) Wind pressures on buildings - probability densities. ASCE Journal of the Structural Division, vol. 101, no. 6, pp. 1255-1267.

Quan, Y. et al. (2014) A Method for Estimation of Extreme Values of Wind Pressure on Buildings Based on the Generalized Extreme-Value Theory. Mathematical Problems in Engineering, Hindawi Publishing Corporation, 22. pp.

Stathopoulos, T. (1984) Adverse Wind Loads on Low Buildings Due to Buffeting. Journal of Structural Engineering. vol. 110, pp. 2374-2392.

STN EN 1991-1-4 (2007) Eurocode 1. Actions on structures. Part 1-4: General actions. Wind actions.

Takeuchi, T. (2009) Effects of section size on aerodynamic forces on an elliptic cylinder under short-rise-time gusts. Proc. of the Seventh Asia-Pacific Conference on Wind Engineering (website: www.iawe.org), Nov. 8-12, Taipei, Taiwan.

Wiland, E. (1968) Unsteady aerodynamics of stationary elliptic cylinder in subcritical flow. Dissertation thesis.

Yan, B. - Li, Q. (2016) Wind tunnel study of interference effects between twin super-tall buildings with aerodynamic modifications. Journal of Wind Engineering and Industrial Aerodynamics [online]. vol. 156, pp. 129-145. Available on: DOI: https://doi. org/10.1016/J.JWEIA.2016.08.001, (accessed at 12/06/2018).

Yu, X. F. et al. (2015) Interference effects on wind pressure distribution between two highrise buildings. Journal of Wind Engineering and Industrial Aerodynamics [online]. vol. 142, pp. 188-197. Available on: http://dx.doi.org/10.1016/j.jweia.2015.04.008, (accessed at 08/06/2018). 